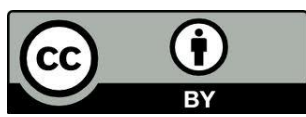

\title{
O APOSTOLADO LEIGO DA IGREJA CATÓLICA NO DECORRER DO SÉCULO XX
}

\author{
Of the lay apostolate of the Catholic Church throughout the Twentieth Century
}

Nadia Maria Guariza Doutora em História do Brasil pelo Programa de Pós-Graduação em História da UFPR. .

\begin{abstract}
RESUMO: Este artigo analisa as propostas de apostolado leigo da Igreja Católica no decorrer do século XX, compreendendo que a ação leiga estava associada à política oficial da instituição. Esta política da Igreja Católica se intensa a partir da metade do século XIX e se constituiu como um dos principais pilares de defesa da instituição na sociedade. $\mathrm{O}$ artigo também demonstra as mudanças e permanências na documentação oficial no tocante ao espaço destinado à mulher na instituição. É perceptível que as encíclicas do início do século XX apresentam uma relação hierarquizada entre clero e fiéis, entre os gêneros e gerações. As encíclicas de Pio XII, a partir da década de 1950, apresentam algumas modificações em relação ao apostolado leigo e na atribuição feminina na instituição. Este processo se intensifica com o Concílio Vaticano II (19621965) que pretendia tornar mais horizontais as relações entre clero e laicado.

Palavras-chave: Gênero; Igreja Católica; Apostolado leigo.
\end{abstract}

ABSTRACT: This article analyzes the proposals of the lay apostolate of the Catholic Church throughout the Twentieth Century, understanding that the lay action was associated with the official policy of the institution. This policy of the Catholic Church intensified in the second half of the Nineteenth Century and became one of the institution's main pillars of defense in society. The article also shows what changed and what remained in the official documentation concerning the place of women in the institution. The encyclicals of the early Twentieth Century can be said to show a hierarchical relationship between the clergy and the faithful and between genders and generations. The encyclicals of Pope Pius XII, from the 1950s, show some modifications regarding the lay apostolate and the feminine attribution of the institution. This process was intensified by Vatican Council II (1962-1965), which intended to make the relationship between clergy and laity more equal.

Keywords: Gender; Catholic Church; Lay apostolate.

Pesquisar sobre a participação leiga na Igreja Católica no Brasil apresenta alguns obstáculos para o historiador, porque as fontes disponíveis são poucas e são permeadas 
pela visão da instituição. Nas fontes encontradas sobre os leigos, percebe-se que a Igreja se preocupou em guardá-las para demonstrar o seu papel evangelizador (GUARIZA, 2003, p. 148).

Não obstante, a possibilidade de encontrar fontes nas atas de reuniões das associações leigas, estas passavam pela supervisão do padre diretor. Neste sentido, escrever a História sobre o movimento leigo no Brasil passa pela análise da documentação oficial sobre o tema, salvo situações em que o historiador possa entrevistar os participantes. Entre a documentação oficial da Igreja Católica encontramse as encíclicas papais e os documentos conciliares.

Como o intuito desse artigo é justamente iniciar a discussão sobre a participação leiga na Igreja Católica no século XX através da análise das encíclicas produzidas nesse período, é necessário contextualizar o período de dificuldades por qual passava a Igreja Católica em meados do século XIX e início do XX para compreendermos a produção do discurso Ultramontano.

O movimento ultramontano e as propostas de apostolado leigo

Desde o século XVI a Igreja Católica sofria ataques contra a sua forma de conceber o mundo e a religiosidade, seja pelos movimentos reformadores de cunho religioso como o protestantismo, seja pela progressiva racionalização da sociedade pelos pensadores da Revolução Científica e do Iluminismo. No século XIX esse processo de laicização da sociedade e questionamento da autoridade tradicional da Igreja se aprofundou, o que provocou uma reação conservadora da Igreja Católica.

Portanto, a partir dos meados do século XIX os papas que se sucederam na direção da instituição foram enfáticos em seus escritos contra os elementos que eram identificados como pertencentes à modernidade, como o socialismo, a democracia liberal, o protestantismo entre outros.

Nesse sentido, a luta contra a modernidade era tema recorrente nas encíclicas do período. Pode-se observar que as encíclicas de meados do século XIX e da primeira década do século XX demonstram que os papas desse período estavam mais preocupados com assuntos de ordem geral, como os Estados Liberais e o Socialismo, ou a defesa dos dogmas e das idéias católicas frente aos ataques dos seus "inimigos". Para 
tanto, acreditavam que a formação do clero era a principal estratégia para vencer as adversidades provocadas pelas idéias modernas.

Por outro lado, as encíclicas do início do século XX, apesar de seguirem as idéias de suas antecessoras, tenderam a aprofundar mais as questões associadas aos leigos, explanando sobre assuntos como o casamento e o apostolado leigo. Portanto, essas encíclicas propunham medidas para tornar o fiel mais presente na Igreja e atuante na sociedade (GUARIZA, 2003, p. 20).

As encíclicas tendiam a culpabilizar os fiéis e a crescente laicização da sociedade pela corrupção moral dos costumes, por isso os fiéis deveriam observar as obrigações e as normas da Igreja. Além de exigir do fiel uma postura moral impecável também as encíclicas apontavam para a necessidade do católico se posicionar de maneira ativa na sociedade para defender os dogmas e preceitos morais da Igreja.

Para incutir essa idéia de militância católica foram utilizadas estratégias como a organização de novas associações leigas e o estímulo à imprensa. Quanto ao uso da imprensa, desde o século XIX a Igreja lançava mão desse recurso, porém de forma precária e restrita à imprensa escrita, sobretudo jornais. Sendo assim, o encorajamento à participação dos fiéis nas fileiras das associações leigas fazia parte do plano conservador da Igreja para recuperar o seu prestígio e poder social, o que influenciou a forma de organização e de atuação das associações nesse período.

As novas normas da Cúria Romana afetaram a forma de organização das igrejas nacionais e das associações de fiéis nas paróquias. Por esta nova perspectiva, as normas válidas eram aquelas submetidas a sua redação e supervisão. As associações leigas deveriam ter o seu manual e regras aprovadas pelo santo pontífice e ser tuteladas por um padre diretor.

Esse processo de controle dos fiéis provocou a perda progressiva de autonomia das associações leigas, pois tinham que observar as normas impostas pela hierarquia eclesiástica. No entanto, com a implantação do catolicismo reformador no século XIX, ressalta-se a importância do clero e da hierarquia, assim como da prática individual do sacramento, ocorrendo um processo de resistência por parte da população na implantação das novas normas (WERNET, 1987).

A implantação das novas orientações romanizadas se efetivou de maneira diferente e gradual nas várias localidades nacionais (AZZI, 1978), tornando o processo 
heterogêneo e descontínuo, sobretudo por causa dos embates entre a nova norma e os elementos resistentes a ela. Um dos campos em que esse embate ocorreu foi justamente o do apostolado leigo.

Desde o século XIX os papas incentivavam a fundação de novas associações leigas e a reorganização de antigas associações, no entanto, no século XX o tratamento dispensado a elas pelos papas se modificou, "pois de espaço para o fiel exercer a sua fé e caridade, as associações se tornaram também um lugar de militância" (GUARIZA, 2003, p. 28).

No contexto de defesa do catolicismo na sociedade, os leigos, nas primeiras décadas do século XX, assumem papel importante, atuando em esferas ligadas ao seu cotidiano. Os fiéis, por meio do exemplo, da caridade e a difusão das "verdades católicas", poderiam dilatar as fronteiras de poder da Igreja.

Não obstante, a Igreja estimular a participação dos leigos na defesa da instituição, havia diferenças entre o trabalho evangelizador de mulheres e homens. Essas diferenças estavam associadas à concepção de masculino e feminino da Igreja e da sociedade da época.

Alguns estudiosos (GIORGIO, 1991) apontam à aproximação da Igreja Católica do público feminino em meados do século XIX devido à idéia de que a mulher seria mais dócil às novas normas do catolicismo romanizado instaurado pelo Movimento Ultramontano. Nesse sentido, inúmeras publicações e associações foram organizadas para atrair esse púbico para o seio da instituição.

Essa aproximação também é percebida pela linguagem utilizada pelos padres que inflamava a afetividade em detrimento da racionalidade, coerente com o embate entre a racionalidade moderna e a afetividade religiosa. É nesse contexto que a Igreja defendeu o culto mariano como expressão do poder maternal de Nossa Senhora sobre seu filho Jesus e sobre os fiéis.

A valorização materna, nesse período, se constituiu como uma das estratégias da Igreja para reconquistar a sociedade, apostando num discurso que pretendia conquistar corações por intermédio das lembranças da infância e da relação mãe e filho, o que mobilizava os fiéis emotivamente (GUARIZA, 2003, p. 78). A Igreja, apoiada na idéia de que a família seria a célula mater da sociedade, acreditava que ao estimular o poder materno cristão no lar poderia reconquistar o poder do catolicismo. 
A intervenção materna agiria de acordo com a teoria dos círculos concêntricos (MANOEL, 1996, p. 49), ou seja, a mãe catequizaria o filho e conquistaria o marido para o catolicismo e estes fariam repercutir as idéias maternas católicas na sociedade. Desta forma, quanto maior o número de mães cristãs, maior o número de famílias cristãs, levando a uma sociedade recristianizada.

Porém, essa ação feminina no lar e na sociedade deveria obedecer aos limites do seu sexo, ou seja, respeitando a hierarquia entre homem e mulher. Nesse sentido, a ação evangélica feminina deveria ser persistente, porém suave e sutil. Para tanto, muitas vezes os padres recorriam ao exemplo de Maria de Nazaré, que apesar de ser superior a José no plano divino, na vida terrena o obedecia com humildade (GUARIZA, 2003, p. $82)$.

Na década de 1920 ocorreu uma mudança no tom das encíclicas que ao invés de portarem palavras dóceis passaram a usar um vocabulário mais viril. Certamente que no século XIX já encontramos analogias militares ao tratar do corpo eclesiástico, porém na década de 1920 elas se intensificaram. Até mesmo em associações femininas pode-se observar essas alusões militares e viris como na criação da Legião de Maria em 1921 na Irlanda.

Zaíra Ary (2000, p. 94-97) afirma que a partir do pontificado de Pio XI (19221939) o discurso oficial da Igreja tendeu a ocultar a condição sexual dos participantes das associações leigas, a uniformizando com um modelo viril para ambos os gêneros. Por isso, em associações como a Legião de Maria encontra-se, em seu manual, terminologias como legionário e soldado, que vinculavam as suas participantes a qualidades e atividade viris 13 .

Poderíamos associar a virilização da linguagem no período a uma possível crise da masculinidade. Segundo Elisabeth Badinter (1993), o processo de virilização da linguagem em determinados períodos é decorrente da crise de paradigmas nas fronteiras entre o masculino e o feminino, ou seja, do que pode ser considerado território de homens e mulheres. Na década de 1920 emergem novas representações da mulher que implicavam em mudanças no modelo oitocentista de esposa e mãe apenas. A mulher moderna deveria exercer a sua individualidade por intermédio da educação e da inserção no mercado de trabalho (COTT, 1991). 
Neste sentido, as mulheres estavam assumindo atribuições bem diferentes daquelas até então preconizadas pela Igreja, ou pelo menos não restritas ao papel de esposa e de mãe. Sendo assim, o território do que seria masculino e do que caberia à mulher se tornaram incertos, levando a uma supervalorização das qualidades masculinas para reafirmar os limites entre os gêneros.

Além da virilização na linguagem presentes nas encíclicas a partir da década de 1920, podemos perceber a necessidade de relembrar constantemente os papéis sociais de mulheres e de homens na ação evangelizadora. Em 1945, Pio XII, na encíclica sobre as associações marianas, se dirige de maneira distinta e separada para mulheres e homens. Para os homens o pontífice se dirige aqueles que "não temem caminhar pelas sendas ásperas da atual condição econômica (...) Homens, finalmente, que, no exercício da própria profissão, detestam a mediocridade e mirem aquela perfeição que a obra de reconstrução (...) reclama de todos" (PIO XII, 1959, p. 6).

Quanto à mulher, Pio XII aponta para mudanças porque passava o papel feminino na sociedade, porém com um tom de temor moral: "É uma crise que abraça a mulher tanto quanto o homem, a juventude feminina como a masculina. A mulher de hoje se encontra também arrastada e turbilhonada na luta pela vida, nas profissões e nas artes, e agora até mesmo na guerra: antes, ela é, mais que ninguém, atingida e ferida por esta derrocada das condições sociais" (PIO XII, 1959, p. 7).

Comparando à visão que Pio XII tinha da vida profissional do homem e da mulher, pode-se verificar que para o pontífice o homem possuir uma vida profissional é comum e demonstra a integridade e a superioridade do indivíduo, enquanto o fato da mulher estar cada vez mais inserida no mercado de trabalho é visto como um dado negativo, pois a expõe à corrupção moral.

Poderíamos pensar que tal diferenciação na perspectiva do trabalho masculino e feminino estava associada à idéia católica da inferioridade feminina, na qual a mulher era mais propensa ao pecado, devido a herança de Eva (ARY, 2000). Sendo assim, as mulheres que trabalham fora de casa estariam mais vulneráveis, não só por sua natureza, mas por conviver diretamente com a sociedade corrupta moralmente.

De qualquer forma, a inserção das mulheres no mercado de trabalho era um fato que não podia ser mais ignorado pelos pontífices, portanto, merecia um posicionamento, que no caso de Pio XII, refletia uma posição conservadora da Igreja ligada ainda às 
idéias ultramontanas de mulher. Por essa visão, a mulher só podia se dedicar à vida religiosa ou ao casamento e aos filhos.

Segundo Maria Salas (1993, p. 22-27), Pio XII demonstrou alguns avanços no sentido de conferir às mulheres e aos homens princípios de igualdade, pois o pontífice entendia que não haveria predisposição inata para atividades femininas ou masculinas. Sendo assim, a maternidade, uma atividade que necessitava de muitos cuidados, poderia ser realizada tanto pela mulher quanto pelo homem. E atividades que seriam, durante muito tempo, atribuídas aos homens poderiam ser realizadas pelas mulheres.

No entanto, a autora ressalta que a visão de Pio XII é ambígua, pois se por um lado reconhece as novas responsabilidades das mulheres na sociedade, por outro lado, recorda as funções peculiares das mulheres, enfatizando a sua subordinação em relação ao marido e os riscos das mulheres quererem se equiparar aos homens (SALAS, 1993).

Como se observou até a metade do século XX a Igreja Católica estimulou a participação dos leigos em suas fileiras porque desejava recuperar o poder social ameaçado pelas mudanças empreendidas pela modernidade. Nesse sentido, a Ação Católica se constituiu como um braço leigo na sociedade para defender os interesses da instituição.

O trabalho evangelizador proposto para os leigos variava segundo a idade, o gênero e a posição social. Esse trabalho evangelizador estava ancorado numa representação de mundo extremamente hierarquizada e conservadora. A hierarquia era perceptível em vários níveis sociais, seja entre clero e leigos, seja entre patrões e empregados, seja entre homens e mulheres. Portanto, a sociedade concebida por esse catolicismo conservador das primeiras décadas do século XX, era clivada por diferenças que estabeleciam relações de poder entre os grupos e se legitimava por meio de argumentos teológicos.

Apostolado leigo em tempos de mudanças

As encíclicas papais demonstram transformações no papel esperado do leigo a partir da década de 1940. Depois da Segunda Guerra Mundial o processo de individualização na sociedade se intensifica, questões até então consideradas de interesse coletivo passam a ser escolha de fórum íntimo, como a opção religiosa. 
Freqüentar a missa e praticar os sacramentos não era apenas um gesto social, tornandose a expressão individual da fé. (VICENT, 1992).

O indivíduo deixou de atuar em nome de Deus para salvar a sociedade, a profissão de fé tornou-se um elemento de identificação do fiel com a religião. Diante destas e outras transformações, a Igreja Católica teve que se adequar aos novos tempos.

O Papa João XXIII, em 1962, anunciou a abertura dos trabalhos do Concílio Vaticano II (1962-1965) que possuía a finalidade de mudar o objetivo e a ação da Igreja Católica. É perceptível duas linhas importantes que serviram de orientação para os trabalhos do Concílio Vaticano II: a de transformar as relações entre o clero e os fiéis e a preocupação com a miséria mundial.

O Concílio Vaticano II apresenta algumas modificações em relação ao laicado como a ampliação da obrigatoriedade de assistir as missas ao domingo para a possibilidade de assisti-la ao sábado, tornando mais flexível para o leigo cumprir esta obrigação; o latim foi substituído pelo vernáculo nas missas, estimulando a aproximação do padre com seus fiéis; e a autorização para alguns fiéis administrarem a comunhão, os chamados ministros da eucaristia.

Quanto as formas de apostolado, o Concílio Vaticano II indica formas individuais de participação que poderiam ser mais flexíveis do que as tradicionais, como a Ação Católica, que deveria seguir as orientações instituídas por Pio XI. As relações entre clero e leigos se tornaram mais horizontais, estes deveriam receber a orientação espiritual e doutrinária dos sacerdotes.

De maneira geral, algumas normas anteriores para os leigos permaneceram, porém o Concílio Vaticano II promoveu modificações no sentido de permitir uma certa autonomia dos leigos para organizar e dirigir novas associações, contanto que estas associações continuassem a seguir os preceitos católicos, caso contrário seriam passiveis de exclusão da instituição (CONCÍLIO VATICANO II).

Não obstante o Concílio Vaticano II indicar uma maior autonomia dos fiéis, o documento também chama a atenção para o cuidado em não dispersar as forças do movimento católico por meio da fragmentação, diminuindo os seus efeitos. Por isso, observa que isso pode ocorrer quando "sem motivo suficiente ou quando se conservam associações de vida já inútil ou de método antiquado" (CONCÍLIO VATICANO II). 
Neste sentido, o documento orienta que os padres e os leigos observem a eficácia das associações com a finalidade de avaliar se as mesmas devem continuar ou deve cessar as suas atividades, para que os esforços fossem concentrados naquelas que prosperam em sua ação. Sobre o apostolado feminino, o documento pouco trata, comentando apenas que elas estavam mais ativas na sociedade e que seria interessante para a Igreja Católica a ampliação do apostolado feminino.

Ao tratar do apostolado leigo, o texto do Concílio está mais centrado nas atividades destes do que na separação de obrigações entre os grupos, ou seja, se os leigos devem se organizar por faixa etária, por classe social ou por gênero. Sendo assim não encontramos referências específicas às mulheres.

Neste texto é relembrado o papel de Nossa Senhora como intercessora entre os homens e Jesus, e o seu papel de colaboradora na Redenção. O texto expõe que Maria ao levar sua vida terrena cheia de trabalhos e de obrigações para com sua família, sempre esteve junto de Cristo ajudando-o em sua obra. A menção a este papel de Nossa Senhora demonstra permanências na forma de compreende o papel feminino na Igreja.

Na encíclica Gaudium et spes, de acordo com Zilda Fernandes Ribeiro (1998), há o reconhecimento feminismo e a sua luta pela igualdade entre homens e mulheres e a necessidade de se criar uma visão positiva do corpo feminino na Igreja.

Maria Pilar Aquino (1997) afirma que outros documentos oficiais da Igreja do período, como as Conferências de Medellín e a de Puebla, empregava uma linguagem de caráter androcêntrico e sexista, contudo propiciou às mulheres uma nova missão e identidade como co-agente da construção da história e da renovação da Igreja.

A convocação e a participação de 23 (10 religiosas e 13 leigas) mulheres nos trabalhos do Concílio Vaticano II é um indicativo que a Igreja Católica estava tentando mudar em relação a forma de conceber o papel feminino na instituição. Apesar da presença das mulheres tenha provocado a criação de anedotas, como sugerir que eram necessários lugares separados para as mulheres e os bispos no intervalo do café.

Não obstante o constrangimento provocado por tais brincadeiras, estas mulheres participaram dos trabalhos do Concílio Vaticano II, integrando comissões e solicitando alterações em textos conciliares (SALAS, 1993, p. 90-91).

O deslocamento da ação e do discurso da Igreja para a criação de um espaço mais democrático na instituição e a preocupação com os pobres, suscitou entre as 
mulheres participantes de movimentos da Igreja, o repensar sobre o seu próprio papel na instituição e na sociedade.

Considerações finais

Analisando a documentação oficial da Igreja Católica no decorrer do século XX é notável que o apostolado leigo possuía um lugar de importância no discurso da instituição. Na Igreja ultramontana o leigo era importante para engrossar as fileiras dos fiéis com a finalidade de combater seus inimigos. Na Igreja pós- conciliar o leigo passa a auxiliar o projeto de democratização da instituição.

No tocante às questões de gênero, principalmente quanto ao papel feminino na instituição, os documentos continuam a expressar uma postura contraditória. No início do século XX a Igreja Católica promoveu a mulher como o esteio moral do lar, mas simultaneamente delegava um lugar secundário a ela na instituição e na sociedade. $\mathrm{O}$ catolicismo pós-conciliar também se mostra ambíguo, pois, ao mesmo tempo, que permite a participação feminina nos trabalhos do concílio, no momento de colocar em prática as propostas continuou a manter as mesmas atribuições ao papel feminino na Igreja.

\section{Referências}

AQUINO, Maria Pilar. A Teologia, a Igreja e a Mulher na América Latina. São Paulo: Edições Paulinas, 1997.

ARY, Zaíra. Masculino e feminino no Imaginário Católico: da Ação Católica à Teologia da Libertação. São Paulo: Annablume,

2000.

AZZI, Riolando. A vida religiosa no Brasil: enfoques históricos. São Paulo: Edições Paulinas, 1983. p. 75-76.

BADINTER, Elisabeth. $X Y$ : sobre a identidade masculina. Rio de Janeiro: Nova Fronteira, 1993.

COTT, Nancy F.. A Mulher Moderna: o estilo americano dos anos vinte. IN: THÉBAUD, Françoise. História das Mulheres: o século XX. Porto: Afrontamentos, 1991.

GIORGIO, Michela de. O modelo católico. IN: PERROT, Michele (org.). História das Mulheres: o século XX. Porto: Edições

Afrontamentos, 1991. p. 199-237.

GUARIZA, Nadia Maria. As Guardiãs do lar: a valorização materna no discurso ultramontano. Curitiba, 2003, p. 148. Dissertação

(Mestrado em História), Setor de Ciências Humanas, Letras e Artes. UFPR.

JOÃO XXIII, Papa. Mater et Magistra. 15 jul. 1961. Petrópolis: Vozes, 1963.

MANOEL, Ivan. Igreja e educação feminina (1859-1919): uma face do conservadorismo. São 
Paulo: UNESP, 1996.

PIO XII, Papa. Sobre as Congregações Marianas. 21 jan 1945. Petrópolis: Vozes, 1959.

RIBERIO, Zilda Fernandes. A mulher e seu corpo: magistério eclesiástico e renovação ética. Aparecida. São Paulo: Editora

Santuário, 1998.

SALAS, Maria. De la promoción de la mujer a la teologia feminista. Malianõ (Espanha).: Sal Térrea, 1993.

VICENT, Gerard. Os católicos: o imaginário e o pecado. IN: PROST, Antonie; VICENT, Gerard (org.). História da Vida

Privada: da Primeira Guerra Mundial a nossos dias. São Paulo: Companhia das Letras, 1992. p. 392-426.

WERNET, Augustin. A Igreja Paulista no século XIX: a reforma de D. Antônio Joaquim de Melo (1851-1861). São Paulo: Ática,

Recebido: $16 / 02 / 2012$

Received: 02/16/2012

Aprovado: $02 / 07 / 2012$

Approved: 07/02/2012 